\title{
"Moving" Discourse: Egyptian Bumper Stickers as a Communicative Event ${ }^{1}$ Ola Hafez \\ Professor, English Department, College of Arts, Imam Abdulrahman Bin Faisal University, Saudi Arabia \\ Corresponding Author: Ola Hafez, E-mail: ohafez3@gmail.com
}

\begin{tabular}{|c|c|}
\hline ARTICLE INFO & STRACT \\
\hline $\begin{array}{l}\text { Article History } \\
\text { Received: August 05, } 2020 \\
\text { Accepted: September } 11,2020 \\
\text { Volume:3 } \\
\text { Issue: } 9 \\
\text { DOI: } 10.32996 / \text { ijllt.2020.3.9.4 }\end{array}$ & $\begin{array}{l}\text { Public discourse, including graffiti, billboards and bumper stickers, is innovative and } \\
\text { dynamic, reflecting and often also challenging social values. While graffiti involves } \\
\text { defacing public property, bumper-sticker (BS) discourse adds a human "touch" to a } \\
\text { metal object, expressing the driver's identity, and turns the street into an arena for } \\
\text { display and communication. The few previous studies of BS discourse explore this } \\
\text { type of discourse as a non-traditional means of communication and as a medium of } \\
\text { political agency in different societies, with emphasis on the US and Israel. Lammie }\end{array}$ \\
\hline $\begin{array}{l}\text { Public discourse, bumper stickers, } \\
\text { content analysis, engagement } \\
\text { markers, speech acts, } \\
\text { intertextuality, identity, Egyptian, } \\
\text { Arabic }\end{array}$ & $\begin{array}{l}\text { and Humphreys (2004) classify a corpus of American BSs into nationalistic, } \\
\text { ideological, commercial, religious, and philosophical categories. Egyptian BSs, } \\
\text { however, remain uninvestigated both linguistically and sociologically. The present } \\
\text { paper, combining tools from content analysis, linguistics and ethnomethodology, } \\
\text { explores how BSs function differently in Egypt based on a corpus of } 581 \text { bumper } \\
\text { stickers on private cars, taxis and shuttle microbuses in Cairo. In terms of content, } \\
\text { they are argued here to revolve around affiliation (e.g. sport, school, and } \\
\text { profession), religion (as an expression of faith and/or invoking God's protection), } \\
\text { and ideology (e.g. photo of Guevara) among other culture-specific conceptual } \\
\text { domains. In addition to the content analysis, the paper also analyses BSs in terms of } \\
\text { engagement markers, speech acts and intertextuality. The paper concludes with } \\
\text { insights regarding the dialogic interactional nature of BSs. }\end{array}$ \\
\hline
\end{tabular}

\section{Introduction}

The discipline of folklore studies has recently developed interest in public discourse as a component of popular culture. Public discourse including graffiti, street signs, newspaper headlines, billboards, and bumper stickers (BSs), is innovative and dynamic, reflecting, and sometimes challenging, social values. While graffiti involves defacing public property and is associated with vandalism or at best aimless rambling, BSs add a human touch to a metal object, assert the driver's ownership of the car and the space it occupies, and turn the street and parking lot into an arena for display and communication. They are similar to graffiti in the sense of being an individual means of self-expression. However, BSs lack the anonymity of graffiti as they are plastered or painted on a personal possession. While seeking individuality by emphasizing the different and unique identity of their users, they still lump their users with others who use the same massproduced stickers ${ }^{3}$. BSs constitute one form of silent interaction between the car in front (the one carrying the BS), and the car at the back, especially at rush hours and/or in crowded roads where bumper-to-bumper driving is the norm rather than the exception. BSs are thus a platform for self expression, exhibitionism and social communication.

In the narrow sense, the term "bumper stickers" (BSs) usually refers to ready-made vinyl stickers with short text messages or symbols plastered on car bumpers. However, in the broad sense, the term includes stickers as well as any textual or symbolic items placed not only on the bumper but also on the sides and the rear window where they are brought closer to eye level. Following Case (1992) and Endersby and Towle (1996), the term may be operationally defined in the present study as any

\footnotetext{
${ }^{1}$ This paper was given at the Symposium on Egypt at the Crossroads, Cairo University in 2008, and later, in March 2009, at the American University in Cairo Conference on Arabic Language and Rhetoric. It was published in 2014 in Cairo Studies in English, Special Issue in Honour of Aida Shaarawy.

K C AL-KINDI CENTER R D FOR RESEARCH AND $\mathbf{R} \mathbf{D}$ DEVELOPMENT

Published by Al-KindiCenter for Research and Development. Copyright (c) the author(s). This is an open access article under CC BY license (https://creativecommons.org/licenses/by/4.0/)
} Your gateway to world-class research

\footnotetext{
${ }^{3}$ Historically, ancient Egyptian obelisks and walls also displayed writing to the public sphere but were static as opposed to the mobile nature of BSs.
} 
textual or symbolic items visible on or through the rear of parked and moving cars, including stickers, inscriptions on the rear window or body of the car, customized license plates (and tag ornamentations stuck on them), objects displayed through, or suction cupped to, the rear-window, and even flashing neon lights incorporated into the rear window, thus excluding front windshield displays (e.g. license or parking permits, and sun guards) and car manufacturer or dealer commercial stickers (presumably not intended by the vehicle driver/owner).

This paper focuses on car side and rear displays of only vehicles carrying Cairo or Giza license plates, i.e. excluding vehicles with license plates other than Cairo and Giza (Egypt) ${ }^{4}$. It is further narrowed down to BSs on three types of vehicles: private cars (henceforth Ps), taxis (Ts) and shuttle (usually commonly called "service") microbuses (Ss). Those types of vehicles clearly differ in terms of drivers' gender, hometown, educational background (literate/illiterate, monolingual/ bilingual/ multilingual), cultural values, socio-economic conditions, and reasons for being on the road (e.g. to commute, to loiter, to make money etc.) These exclude BSs on buses, trucks, vans, etc. as these probably embrace cultural values which may differ considerably from the categories in question. In addition, the analysis is restricted to the language of BSs, thus not handling the color, size, location, shape, font or other semiotic features of such texts. For this reason, drawings, pictures and objects (e.g. amulets, trinkets) are excluded from the corpus. The type and age of the car were not recorded, neither were the age and gender of the driver as they were either parked with no driver in sight or were driving in heavy traffic, which did not always allow the perusal of cars, and because there was no guarantee that the driver is the owner of the car or the source of the BS (esp. in the case of family cars).

As motor vehicles occupy huge spaces, take up large amounts of time commuting, and consume valuable chemical resources, BSs thus play an important role in turning such impersonal, inanimate objects into a public space for communication, for recognition of the driver and the car as a symbol of superiority of the car driver, conflict with other drivers and/ or solidarity between like-minded individuals. The study also aims to investigate the values underlying BSs, being shaped by and instrumental in shaping social practice (Fairclough 1989), i.e. constructing the roadway and reflecting individuals' social vision.

As a communicative event, BSs involve at least two participants: the addresser and the addressee(s) (See Goffman's (1979) distinction between different types of addressers and addressees.) The addresser here is not necessarily the same as the author (i.e. the manufacturer of the sticker in the case of mass-produced stickers, whose purpose is to make drivers buy the sticker). The addresser is the person who chose to plaster, inscribe or attach a certain sticker, thus adopting it and showing preference for this sticker over another or none. The identity of the original author is thus transferred to the actual addresser. On the other hand, the intended and actual addressee(s) include the pedestrians and the occupants of other vehicles, especially the driver of the car behind. The actual addressees include both individuals personally known to the addresser (i.e. friends and neighbors) as well as anonymous viewers (i.e. the majority of readers being unknown to the addresser, theoretically including the entire population, and creating a communicative space of the whole public who may be willing or unwilling to participate in this popular discourse of stickers). As exposure cannot be planned or calculated but rather decided by where a particular car travels or parks, the audience, thus, consists of whoever happens to be exposed to the message. Though the addresser is anonymous for the majority of the readers and is not committed to interact with them, BSs create imaginary communities of people who communicate their ideas, interests, and /or identities.

\section{Literature review}

Little scholarly work has been done on the use of BSs as a form of public discourse, folklore, and popular culture. The little work done so far comes mainly from the US and Israel, pointing out the preponderance of political BSs (e.g. Newhagen and Ancell 1995; Endersby and Towle 1996; Bloch 2000). Different approaches have been followed in analyzing BSs, ranging from content analysis (e.g. Case 1992, and Lammie and Humphreys 2004) to cultural (e.g. Chiluwa 2008), sociolinguistic (e.g. Newhagen and Ancell 1995), and linguistic approaches investigating speech acts (e.g. Bloch 2000).

Many studies of BSs analyze them using content analysis, identifying different categories of BSs. One of the earliest studies of BSs is that by Case (1992), where he identifies six categories of BSs, namely ideological, political, philosophical, commercial, self identity/personal and other. He computes their frequency of occurrence and concludes that ideological, philosophical and commercial ones were the most frequent. However, he does not distinguish between different types of vehicles or drivers.

\footnotetext{
${ }^{4}$ When the corpus was collected in 2008, all Cairo and Giza cars carried license plates showing a) the type of car (private, taxi, cargo, diplomatic, etc.), b) the governorate (e.g. Cairo, Alexandria), and c) the license number. This was only a few months before a new format of license plates was introduced in 2009 using colour coding and alpha-numerical combinations to indicate the type of vehicle and the governorate, respectively.
} 
In an exploratory study, Banning (1996) also categorizes campus BSs by thematic content. He analyzes BSs collected from different campus parking lots and compares students, staff and faculty BSs by topic. Banning analyses data in the light of the car make, model, year, and type of vehicle. He uses participant observation, interviews, observations and documents and finds out more frequent use of BSs and similar artifacts on students' vehicles than those of faculty and staff.

Lammie and Humphreys (2004) also analyze BSs in terms of thematic content in relation to car condition (good, moderate, or old) to study how drivers of different vehicles express political and social views. They also interview people about other motorists' BSs. They conclude by classifying BSs into patriotic, commercial, geographic, educational, philosophical, sport and political categories.

Another content analysis is the one conducted by Newhagen and Ancell (1995), following a sociolinguistic approach. They analyze BSs by topic and emotional valence and intensity in neighborhoods selected for their racial mix (Black and white) and economic status (high, medium and low-income levels). They conclude that lower-income blacks use more stickers than white and/or higher income drivers who have other avenues for expression, thus classifying themselves in various socioeconomic groups trying to connect with successful social groups, and showing their likeness to their class. Topics handled in the BSs include sports teams, schools, as well as political and social issues.

Also Chiluwa's (2008) study of the religious BSs used in Nigeria's busy capital, Lagos, analyses BSs as a means of expressing group membership and protest or rejection. Viewed as social practice, BSs were collected and categorized into 3 subgroups: social vision, individual/group identity, and reaffirmation of faith, thus revealing institutional practices and systems of beliefs and defining group and individual identities. BSs thus become a means of communication and provide a platform for spiritual and psychological expression.

In contrast, Endersby and Towle (1996) analyze BSs as a form of identification and expression of group affiliation and solidarity with a group sharing common beliefs. They examine a corpus of BSs collected over 2 weekends before the 1992 elections and classify them according to their expressive content in the light of political and non-political messages. They conclude on the use of political BSs as a form of identification and solidarity with a candidate/group sharing common beliefs while non-political ones handle educational, commercial and safety-related topics.

Similarly, in the website entitled "Bumper sticker stupidity", Shore (2003) comments on the exhibitionism, self-expression, electioneering, and preaching functions of BSs. He interprets anti-Bush BSs as telling something about the driver (not the elections) as sophisticated and not fooled by a simpleton. He also comments on the role of BSs connecting like-minded individuals.

Bloch (2000) remarks that while political BSs are only marginal in the US, they constitute the majority of BSs in Israel. She analyzes Israeli BSs as a form of self-expression and as a speech event in relation to participants (i.e. sender, addresser, audience, and addressee) and purposes within the framework of speech act theory, identifying a number of functions including self-expression, criticizing, encouraging and ordering. These reflect social norms, affirm Israel's cultural identity and change the structure of political agency.

Noble and Baldwin (2001) analyze BSs as a form of appropriation. They study BS use in relation to the type and age of the cars they are plastered to. They conclude on how profanities and sexual aggression expressed in women drivers' BSs function as "a symbol of female breaking out" (p.83). They classify BSs into ones of clothing brands, car companies, political and cultural allegiances, environmental or religious ethics, and football clubs. They comment on how BSs individuate and/or group drivers, by marking difference or sameness. They also comment on BSs which derive from sub-cultural discourse alien to many outsiders and resist final interpretation or challenge conventions about public discourse. BSs also blend the traditionally feminine and its reverse, thus signifying individuality and assertiveness through the use of foul language, referring to the mad, the foolish and the obscene, as markers of power, strangeness, difference, producing fear and anxiety.

Similarly, Salamon (2001) analyzes political and religious BSs in Israel and explores their diverse and at times contradictory interpretations, through the use of semi-structured interviews with drivers regarding the stickers appearing on their own vehicles. She concludes on the inherent ambiguities and multiple meanings of BSs as a forum for intertextual negotiation.

In contrast to these studies of content, very few studies address the language of BSs. Kurzon (1997) studies BSs as direct address between two cars (hence the use of first and second persons as well as distal and proximal deictic expressions like "here" and "there", and puns like "ahead" (meaning "in front" / "superior") and "accident" meaning "chance" or "collision"). He relates such linguistic choices to the humorous impact of BSs. He also comments on intertextuality in Bs as allusions to other texts. Another study which addresses language though in relation to graffiti rather than BSs is the one conducted by 
Nilsen (1980). This study of the language of graffiti points out the use of homonymy (e.g. "non-prophet organization"), punning re-division of words (e.g.. If "pro" is the opposite of "con", then what's the opposite of "progress"?). He underlines the economy of graffiti employing the minimal number of words, and the use of imperatives to engage potential readers. However, no studies have been made to date on Egyptian BSs, nor on their role as a communicative event, nor have any studies of BSs compared their use by different types of vehicles. The present paper intends to fill this gap, studying how Egyptian BSs used by different types of vehicles function as a communicative event.

\section{Research questions}

This paper examines the effect of the type of car (Private/ Taxi/ Shuttle or service) as an independent variable on two dependent variables, namely 1) Engagement (e.g. pronouns; speech acts; intertextuality; language choice), and 2) Conceptual domains of BSs (through Content analysis based on lexical items, synonyms, as well as hyponyms). In studying such variables, the present paper attempts to investigate how BSs constitute communicative events. It attempts to answer the following questions:

a. How do BSs on private cars, taxis and shuttle buses engage with addressees (other drivers and pedestrians)?

b. What conceptual domains are addressed by BSs on private cars, taxis and shuttle buses?

\section{Data collection}

All and only BSs that were clearly visible from the rears and the sides of private cars (Ps), taxis (Ts) and shuttle buses (Ss) were collected over the period of 6 months (from March to September 2008) These were collected randomly from cars surfing or parked in the streets of Cairo and Giza (including different districts like Heliopolis, Tahrir, Manyal, Maadi, Giza, Agouza and Dokki). While some cars had no stickers at all, others used one or more BSs; however, BSs were collected regardless of the number of cars that had them. Moreover, repetitions of the same BS wording were deleted from the corpus. Excluding repetitions, the total number of BS texts is 581, whose distribution is as follows: 270 BSs on Ps (Private cars), 140 on Ts (Taxis) and 171 on Ss (Shuttle or "service" microbuses). Almost equal numbers of BSs were originally collected from each car type, but those that involved repetition were excluded, hence the seeming lack of exact balance.

\section{The analytical framework and methodology}

Regarding BSs as an instance of discourse, ie written language in use, functioning in a social context, the present study broadly touches upon what Halliday (1985) calls the metafunctions of discourse, particularly the ideational and the interpersonal functions. However, it relies on other models and methodologies for its analytical tools, mainly the work of Hyland (2005) in metadiscourse for engagement markers establishing the relationship between addressers and addressees, and the work of Krippendorff (1980) in content analysis in analyzing the conceptual domains of the BSs.

Hyland (2005) identifies engagement markers that address readers as participants and maximize the bonding between addresser and addressee through the use of first and second person pronouns and vocatives, and pull them into the discourse through the speech acts of rogatives, directives and expressives, as well as references to shared knowledge.

As for conceptual domains, these indicate the values and preoccupying content expressed by BSs, which can be uncovered through content analysis (Krippendorff 1980), a methodology that enables the researcher to study large amounts of text and systematically identify the frequencies of most frequently used keywords and detect the more important structures of its communication content and categorize considerable amounts of textual information according to a certain theoretical framework, providing at the end a meaningful reading of content under scrutiny.

The methods used by content analysis were used by the present study to categorize BSs into a number of conceptual domains, mainly based on lexical choice. To increase its reliability, three expert linguists were given a questionnaire including the list of BSs and a list of categories adapted from the literature to the nature of Egyptian BSs. They were asked to assign the BSs of the corpus to one category or another by reliance on exact lexical items or synonyms of them. Due to the difficulty encountered in assigning certain BSs to certain categories, semi-structured interviews were conducted with drivers of different car types as well as other (un)willing participants in this form of public discourse including pedestrians, passengers, onlookers, etc. to identify the possible interpretations of certain problematic BSs. It is with the assistance of such ethnomethodological techniques that meanings could be assigned to BSs with a certain degree of reliability and conclusions could be reached regarding the possible intentions of drivers using them.

\section{Engagement markers}

The interpersonal function is represented in how drivers relate to their addressees through a number of linguistic choices. These involve pulling readers into the discourse as discourse participants through the use of a) pronoun use as explicit 
reference to addressers and addressees; b) certain speech acts, especially (rhetorical) questions expecting no response but building solidarity and arousing interest in performing an action; c) references to shared knowledge, namely intertextuality; and d) the language used in BSs, whether Arabic, English or other languages.

\subsection{Pronoun use $\mathrm{e}^{5}$}

One device used to maximize the degree a text engages readers is the use of first and second person pronouns (Hyland 2005). This includes not only self mention (i.e. reference to the driver using first person pronoun singular), but also second person pronouns referring to addressees, and inclusive "we" including both addressor and addressee.

BSs often involve first-person reference to the driver and /or the vehicle through the use of the first person pronoun or nouns referring to either. First person pronouns are used to personalize the car as a speaker as in the following BSs: “I'm a baby Mercedes," "Back off!/ I'm not that kind of car!" and "ما تبصليش بعين رضيه بص اللي اندفع فيه" (i.e. Don't look at me with an evil eye; look at what I cost). In contrast, the first person pronoun is also used, as expected, to refer to the driver and voice his/her opinion. Examples include "Answer my prayers/ steal this car," “If u touch my car / I'll touch ur girl!," "يقيني باله يقيني" (i.e. My faith in God protects me) and "اعز الناس في الدنيا أمي" (i.e. The dearest person to me is my mother). Sometimes, first person use is ambivalent, accepting both "car" and "driver" readings. Examples are "Don't follow me / I'm lost too", "I'm

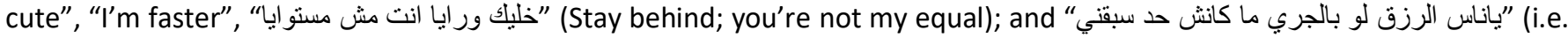
Folks, if sustenance came through speeding, no one would outstrip me). Additionally, plural first person pronoun "we" is

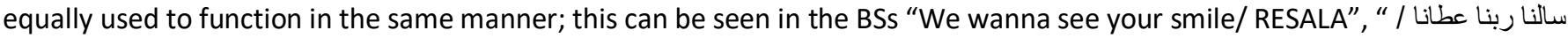
لا عز و لا غنا النزاهة " "i.e. We asked the Lord and he gave us but people's eyes won't leave us [alone]"; and "و عيون الناس مش ساييانا "طبعنا" (i.e. [I have] Neither high rank nor wealth; respectability is our nature). Plural first person specially features in BSs expressing supplication where the speaker pictures himself/herself as one of many slaves of God asking His forgiveness, bounty, etc. An example is "قلى لن يصيينا الا ما كتب الله لنا" (i.e. Say nothing will happen to us except what Allah has decreed for us). On the other hand, first person pronoun use is sometimes avoided through explicit third person lexical reference to the driver, thus minimizing engagement. Example are "Driver carries no cash / he's married" and "Pass quietly / driver asleep" where the driver avoids involvement and contact with other drivers through claims of being broke or asleep. When looked at quantitatively, such uses of engagement are of comparable frequencies of self mention across vehicle types $(P=16.6 \%$, $\mathrm{T}=15.7 \%$, to $\mathrm{S}=14.6 \%$ ).

Another engagement device bonding driver and onlookers on the road involves the use of second person pronoun by all three vehicle types alike. It is used in $9.6 \%$ in $\mathrm{P}, 14.3 \%$ in $\mathrm{T}$, and $21 \%$ in $\mathrm{S}$. In other words, at one extreme private cars seem to use it least, attempting less contact with other drivers while at the other extreme, shuttle BSs seem to employ noticeably more frequent use of second person pronouns. The use of second person pronoun functions to pull the readers into the discourse. This use of "you" includes both addressee-specific as well as indefinite reference. Addressee-specific second person pronouns refer to other drivers. Examples are "I may be slow / but I'm ahead of you", "If you can read this / you're

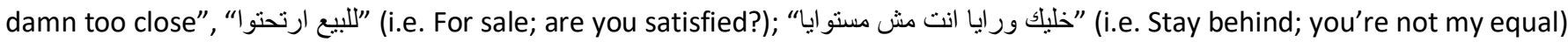
and "خليك في حاللك" (i.e. Mind your own business). On the other hand, the second person pronoun is also used for indefinite reference applicable to any one, (comparable to the use of the indefinite pronoun "one"), not just other drivers or pedestrians. Consider the BSs "Marriage is the only war where you sleep with the enemy"; "Smile/ it's the second best thing

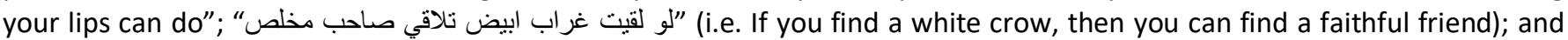
the bilingual BS “ أوقف المخدرات / غير حياتلك "stop drugs ... change your life". As in advertising, this use of second person address tries to engage unwilling and/or inattentive potential recipients. Second person reference is also used in proverbial and Quranic advice, again with indefinite reference. Examples include "البقرة 2 : 281) (i.e. Be fearful of the day when you go back to the Lord); "كيف تغفل للك عين وطعامك وشر ابك من حرام" (i.e. How can you sleep [peacefully] when

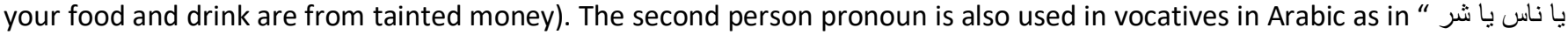

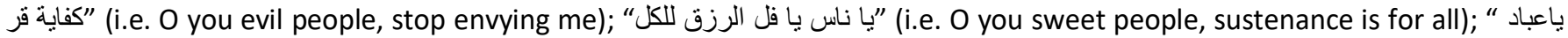
اله اذكرو الله (O you slaves of God, remember the Lord). Vocatives are often addressed to an imaginary third party that seems to be omnipresent on the driver's mind as in the BSs "بركة دعاكي ياأمي" (i.e. O mother, the blessings of your prayers), and " لعبناك يابو مححد (O Abu-Mohammad, it's your game). This use includes the frequent address to Prophet Mohammad (PBUH) as

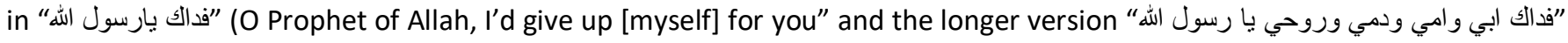
(i.e. O Prophet of Allah, I'd give up my father, mother, blood and soul for you". It is also found in supplication and prayers such as "اليارب سترك" (i.e. O Lord, [grant me] your protection) and "اللهم اعطني خير ها و اكفني شر ها" (i.e. O Lord, give me its good and protect me from its evil).

\footnotetext{
${ }^{5}$ Reference is made to corpus items belonging to six categories: PE (Private car English BSs), PA (Private car Arabic BSs), TE (Taxi English BSs), TA (Taxi Arabic $\mathrm{BSs}$ ), SE (Shuttle English BSs), and SA (shuttle Arabic BSs).
} 
Finally, inclusive "we", i.e. plural pronoun referring to both addresser and addressees, involves driver and on-lookers in the communication as having some joint interest and being in the same boat. Examples are "Let's not meet by accident"; " حسبنا اله " (i.e. For us Allah suffices and He is the best Guardian); “نعم الوكيل (Say nothing will happen to us

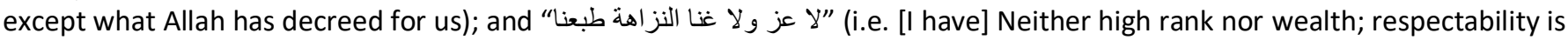
our nature). In terms of frequency of occurrence, inclusive "we" is present but with very little frequency (less than $0.02 \%$ ) in all three vehicle types alike.

In short, first and second person pronouns establish driver-onlooker communication and turn the BS into a dialogic tool. The street is thus turned into an arena for communication, interaction and awareness of the space the car occupies in relation to other drivers as well as pedestrians and onlookers in general.

\subsection{Speech acts}

The dialogic function implicit in first and second-person pronoun use is also apparent in some speech acts (Searle 1976) expressed through BSs. The speech act category of rogatives, mainly consisting of rhetorical questions expecting no answer, simulates interaction, builds rapport between drivers and onlookers, and arouses interest in trying to respond with the appropriate action. Examples include "Why no gain with zero pain?”; “Why not hot girls with ZERO boyfriends?”; " شيخ قعيد أيقظ

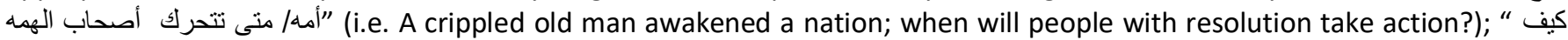

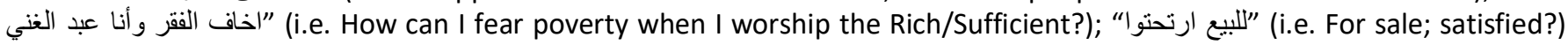
Though these questions are rhetorical, requiring no response, but rather implying that such things should or should not exist, such questions make a silent response relevant; hence the dialogic nature of such BSs. All in all, rogative speech acts occur at a very low frequency in all vehicle types alike: $(P=0.01 \%, T=0.35 \%, S=0.17 \%)$.

Similarly, expressive speech acts, i.e. BSs expressing the driver's psychological state toward a particular state of affairs, (e.g. thanking, apologizing congratulating, were also observed in the corpus though at a very low frequency. Examples include the welcoming "Pleased to beat you", the exclamatory "Mondeo" [sic] (i.e. My God!), and the apologetic "معلث يا صاحبي" (i.e. Never mind, pal) and "لا مؤ لخذّ" (i.e. Sorry).

Another speech act that occurs more frequently in the BSs corpus (ranging from $15.5 \%$ to $14 \%$ ) is that of directives, i.e. attempts by the addresser to get the addressee to do something (Searle 1976). Directives are often realized through imperatives, like "Answer my prayers/ steal this car"; "Don't follow me"; "Follow me if you can"; "Just do it"; "Don't do it"; "Help - I'm being kidnapped"; "Mind the gap"; "Pass quietly - driver asleep"; "Shut up and drive"; "Think globally - act locally";

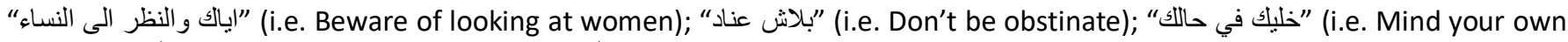

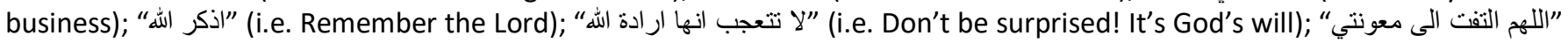
(i.e. O God, remember to help me!); “ما تبصش كده ياعبيط الحلوة دي بالتقسيط" (i.e. Don't look like that idiot! It’s [purchased] by

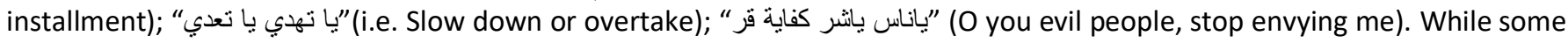
BSs tell readers to do something for their own benefit, like asking God for forgiveness, others are intended for the driver's benefit, like asking onlookers not to do harm to others (including awarding the evil eye). At any rate, such directives make a response highly expected, thus providing a dialogic nature to BSs in communicating with other drivers.

\subsection{Intertextuality}

Many BSs allude to and build on onlookers' shared knowledge, through the use of "intertextuality". According to Kristeva (1991), examples of intertextuality are instances of language that refer to or echo previous texts. By alluding to shared knowledge, BSs engage the readers. Examples of intertextuality found in the corpus include allusions made to other texts such as famous religious quotes on the one hand, and mass-mediated sources such as films, songs and soap operas on the other in addition to a host of other scripts.

Examples of intertextuality include allusions to religious texts. One of these is the BS, "لمن الملك اليوم اله الواحد القهار (i.e. Whose will be the Dominion that day? That of Allah, the One, the Overpowering), a verse taken from the Quran word for word referring to Doomsday, possibly as a means of attesting that only God Almighty has power over all creatures (on Doomsday). Another religious reference is implicit in the BS "البطل الروماني" (i.e. the Roman hero), alluding to St. George (aka "Mari Gerges", well known among Egyptian Christians for self sacrifice and often cited to invoke good luck and bounty).

Intertextuality is also evident in BSs citing titles of films, songs and soap operas verbatim. These include the film titles " معلش "ساصاحبي" (i.e. Never mind, Pal); "سهر الليالي" (i.e. Sleepless Nights) and "المواطن مصري" (i.e. The Citizen is Egyptian); the songs "قفرق كتير" (i.e. Makes a Great Difference) and "حكايتي مع الزمان" (i.e. My Life Story); and soap operas like "مانك "(i.e. My Soul Mate). Some BSs allude to film titles with variation for humorous effect like the BS "الزعان "i.e. The Pacha [or police officer] is not a Student)) alluding to the film entitled "الباشا تلميذ" (i.e. The Pacha is a Student), and thus by negating the 
statement made in the film title, implying that the driver has the status of a respectable Pacha, but not that of an immature student. Similarly, many BSs especially ones painted on shuttle buses and taxis allude to main characters in Egyptian soap operas and films, usually with a heroic character of a "tough guy" like "حسن ارابكل" (i.e. Hassan Arabesque) and "نتئو" (i.e. Tito), foreign actors in action films like "ألبتشينو" (i.e. Al Paccino), or even the female heroic characters "Xena" and "Vampire Slayer", all of whom play major roles in action films and soap operas. Other BSs were used humorously, alluding to funny characters like the vulgar, drunken dropout "بوحة" (i.e. Boha, a nickname) or the cartoon figure "Fido dido" representing a cool, relaxed attitude.

Other BSs allude to different scripts for humorous effects like "Normandy 3", alluding to the real and fictitious shipwrecks of "Normandy" and "Normandy 2" respectively, thus making fun of the car the BS is painted on as "sinkable" and possibly a piece of junk, good for nothing. Another BS alludes to the script of phone calls; the BS "Number busy" implies that the driver is unavailable for personal communication. Similarly, the BS "Devil inside" alludes to the computer logo "intel inside" from the computer script, implying that the car is programmatically equipped with a devil, possibly advising other drivers to make way. A similar BS is "الجوكر وبس" (i.e. Only the Joker), alluding to the cards script, and implying that the driver can fit anywhere whenever the need arises. Interviewees interpreted this to be a free-lance driver's nickname conveying his availability for work for shuttle microbus owners looking for drivers.

Some other BSs even seem to allude to previous BSs like "family on board", "naughty person on board", or even "devil on board", all alluding to the original "Baby on board", and all requesting other drivers to make way while making fun of the passengers on their car. Similarly, the BS "Don't do it" followed by a cross sign alludes to the Nike log and motto "Just Do It" with a tick, thus implying humorously that onlookers are advised not to buy Nike products. In a similar fashion, the BS "لليع " لليع "For "بجد" (i.e. For sale; serious!) alludes to frequently encountered "For sale" and "للبيع", which are thus implied to lack the intention to sell and to be possibly painted solely as an amulet to avert the evil eye. Also alluding to a frequently encountered predecessor is the BS "Forget about world peace / Visualize using your turn signal", which alludes to the frequently encountered BS "Visualize World Peace" addressing humanistic issues of peace to all countries of the world. The more recent BS advises on-looking drivers to forget about "big" issues and focus on driving properly, including the use of turning signals. All in all, BSs manipulate intertextuality to refer to shared knowledge and engage onlookers in dialogue in public.

\subsection{Language choice}

The fact that Egyptian car drivers choose to plaster or paint BSs in a language other than their own was noticeable more frequently on private cars (84\%) than the other two categories ( $27 \%$ on taxis and $16 \%$ on shuttle buses). Thus, P BSs are predominantly English-mediated while Taxis and shuttle buses are predominantly in Arabic. Such foreign language use of English, French or even languages rarely spoken in Egypt like Japanese or Chinese ${ }^{6}$ plays a role in individuating the driver from non-speakers of foreign language(s) while bonding with like-minded speakers of those languages. While building rapport with English speakers, English BSs are opaque to drivers not competent in the language. Since foreign language use was most frequent in private car BSs (84\%), it seems to imply prestige and social distinction, implying a higher socio-economic class, having studied English at an English language school, and/or travelled abroad. Similarly, a few private cars plaster websites such as "Tawdeeb.com/ ...", "www.jeep.com.eg" and www.papasbar.com, thus implying not only knowledge of foreign language(s), but also that the driver is well versed in computers and internet use, further distancing the driver from any computer-illiterate onlookers.

There is also a noticeable amount of code-mixing in the BSs, where BSs either mix Arabic and English as in "Aboul Eyes", probably for the proper name "Aboul-Oyoun" or "Aboul-Enein" (literally, the one with the eyes), or "Ahmed El King", for the proper name Ahmed followed by the royal quality of being King or leader in one way or another. A few BSs also practice what may be termed "script-shifting", using Roman alphabet in writing Arabic, thus merely transcribing Arabic into Roman letters. Examples include the BS "rewesh tahn", a slang term for "cool" or "awesome"; and the BS "Ya semmm" (i.e. you beast! or how horrid!). There are also straightforward literal translations from Arabic as in the BS "Go slow or pass!" for the Arabic BS "يا تهدي يا تعدي" (i.e. Slow down or overtake). Such foreign language use in BSs demonstrates the drivers' wish to affiliate with users of foreign languages, especially English despite their varying degrees of competence in English or other foreign languages, thus bonding and relating to other literate, well-educated, bilingual drivers.

In short, the use of first and second person pronouns, speech acts involving addressees in an expected course of action, intertextuality building on shared knowledge and use of foreign languages all combine to maximize the interactive character

\footnotetext{
${ }^{6}$ There were only three French BSs and two Japanese / Chinese ones in the whole corpus, all plastered on private cars. Though the number may seem insignificant, the mere use of such rarely spoken languages can have implications on the drivers' wish to communicate with or dissociate from certain categories of onlookers.
} 
of BSs. By using such devices, drivers form a community, turn the street and parking lot into an arena for interaction, assert their ownership of their vehicles and the space they occupy, seek or at least simulate interaction with other drivers in particular and onlookers in general.

\section{Conceptual domains of BSs}

In previous studies of American and Israeli BSs (e.g. Case 1992), the conceptual domains addressed by BSs were found to include political, philosophical, ideological, commercial, safety (e.g. baby on board, no drinking), and religious content. The present study applies content analysis to Egyptian BSs to find out how they differ from BSs used in other cultures. In analyzing Egyptian BSs conceptually, the categories used in the analysis are bound to overlap so that it is possible for one sticker to fit into multiple categories at the same time. Such categorization is a matter of convenience for the purposes of the analysis.

\subsection{Identity}

A major category of BSs involves identity if the car driver/owner, i.e. how drivers define themselves and wish to present themselves to others. This includes references to oneself, group to which one belongs, institution, favorite sports and favorite club, school or educational affiliation (even if for a brief period). Identity-related BSs are thus expressions of unique personal identity through symbols representing one's interests, affiliations, values and claims to recognition.

\subsubsection{Name}

One way drivers express their identity is through writing their names and the names of their loved ones on their valuable possessions, namely their cars. BSs carrying names are most frequent on $\mathrm{S}(13.4 \%)$ and taxis $(12 \%)$ while they are quite scarce on P cars (only 0.04\%). They include the full name (e.g. "Ahmed el king", "Mohamed Elbhiry" [sic.], "Tamer El-Shayeb"; the last name like "El-Sedawy"; or the first name of the driver him/herself or loved ones (possibly children). Examples from P cars include "Marian", "بدور" "Amr \& Ramez", and "بوسف". They also include nicknames like "Bebo", "Solom", "Tito", "Gogo",

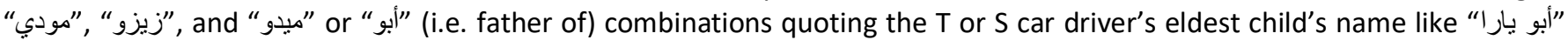
(i.e. Father of Yara) and "ابو يوسف" (i.e. Father of Youssef). Nicknames involving praise are also frequent on T and S cars, like

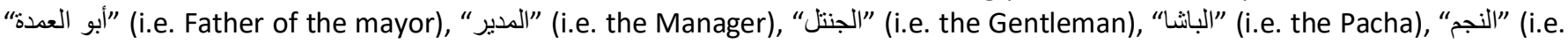
the star), and "el Professor". Religious identity is often implied through personal names like "Mohamed" or "Bishoy" as well as "الخواجة المصري" (i.e. the Egyptian Christian) and "Western Christian John) (i.e. Westerner and/or Christian). Finally, name-based BSs include names of major roles in films, soap operas and animation characters like "Tito", "بولحب" and "Bakkar" as seen in section 6.3. above.

BSs also include names of loved ones usually denoted by expressions of love and endearment. These are frequently

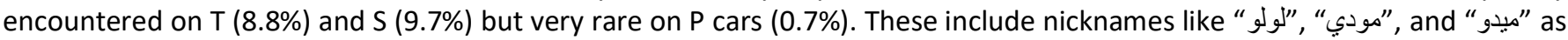

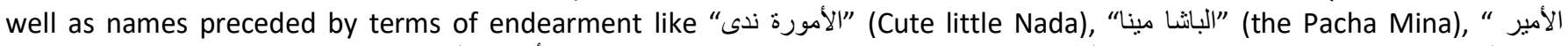

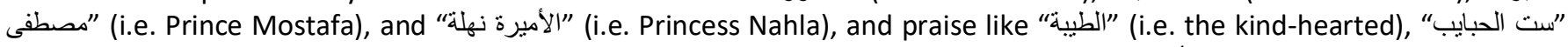
(i.e. the darling one ie mother), referring to one's mother, "ملك روحي" (i.e. My soul mate), "بنت الأكابر" (i.e. the daughter of the great), referring to loved ones without naming them or specifying their relationship. Reference to one's children is also implicit in men's "أبو" (Father of) combination names as explained above.

Another naming practice found in the BS corpus refers to the car name, found exclusively in S cars at the frequency of $6.2 \%$.

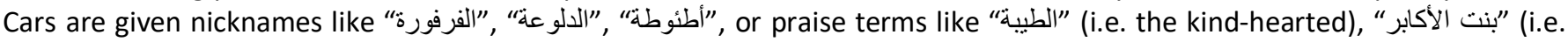
the daughter of the great), or "jumpo" [sic.]. They are also pictured in metaphorical terms as "البلاوزي" (i.e. the bulldozer) and " اللنش" (the yacht) implying their strength and ability to cruise the streets assertively, or even aggressive ones like "كيداهم" (a) tease, or spiteful), indicating liking for conflict and assertion of supremacy.

\subsubsection{Sport}

Another conceptual domain encountered in the corpus in relation to identity addresses sport. The three car types differ in frequency and quality of sport-related BSs. In terms of frequency, BSs found in P reached $6.6 \%$ as opposed to $2.1 \%$ of $\mathrm{T}$, and $1.7 \%$ of $S$ cars, thus showing more interest and preoccupation of private car drivers who seem to have the tie and interest for this type of spare-time luxury. In terms of quality, of all the different types of sport, the most recurrent one is football, which is addressed by all three car types. Many BSs relating to football name local clubs like and international teams. This often represents the drivers' favorite football team, whether local such as "Al-Ahly", "النادي الاهلي", or international such as "Arsenal"., "B C Barcelona", "Juventus", "Manchester United", and "Chicago Bulls". One frequently encountered BS even includes an invitation to support a specific club as in "Follow me to Al-Ahli Red Devils". BSs also single out a specific player as the driver's favorite as in "Zamalek 18 Shekabala" and "Mido". Only P cars, however, refer to other sports and to sportswear. They refer to other sports like jogging in the BS "Around the Track", and basketball in "NBA" (for National Basketball 
Association), and "Wilson", a basketball brand. They also name certain brands of sportswear like "Puma", "Nike", and the Nike logo and motto "Do it". They even name a few gymnasium clubs like "Smart Gym", "Gold's Gym" and "Vein Gym". In this way, P car BSs seem to imply an athletic identity necessary to image making.

\subsubsection{Alma mater}

The topic of education is addressed exclusively by $\mathrm{P}$ cars at a frequency of $6.9 \%$ of all P car BSs. This category includes school and university affiliation. For instance, universities abroad like "UCLA", "Harvard", and "University of Toronto" BSs imply that the driver is not only (likely to be) affluent, but also a well educated top thinker, possibly with a leading profession, and elitist socio-economic and personal values having invested in a distinguished foreign education. A show of superior education is also implied by BSs naming high-tuition private universities like "The American University in Cairo"; "Arab Academy for Science and Technology"; "Modern Academy Maadi"; "MSA University"; and "Misr University for Science and Technology". P cars also featured prestigious faculties in state universities, usually leading to guaranteed high-paying careers like "Faculty of Pharmacy", "Faculty of Engineering; "Faculty of Computer Science"; "FEPS/ Faculty of Economics \& Political Science / English Section" and "Police Academy". Similarly is the naming of a French school, namely "Jésuites". The impression by all such alma mater BSs is one of higher fees, and eliteness of values and promising career opportunities. Even when citing a not-soprestigious educational institution, namely the Faculty of Commerce, it is cited in French in the BS "Faculté de Comerce/ Université de Cairo" [sic.]. The commonplace "Faculty of Commerce" is thus upgraded through the use of French. It is noteworthy that two of the three French BSs of the corpus appear in this category as evidence of foreign education in languages other than Arabic and the now-commonplace English education.

\subsubsection{Profession (authority figure)}

Another category of BSs is occupational affiliation BSs referring to the place of work or the type of profession such as the police, justice, dentists or doctors, all being status related. Expectedly, this category is exclusive to $\mathrm{P}$ cars at the frequency of $2.9 \%$, with the exception of such signs as "Taxi" or "City Cab" or other company names stuck on some T cars to indicate the taxi company they belong to. It is noteworthy that there were no BSs of less prestigious professions such as real-estate brokers, butchers or plumbers, which are of lower social standing despite their high income level. Examples include BSs such as "Dental society", "مجلس الثعب" (People's Assembly), "القضاء العالي" (i.e. Justice), (i.e. supreme court of justice), "المستشارون / المنتدى القضائي" (i.e. councilors/ the judicial forum), "الجمهورية/صحافي" (i.e. "Gomhouria newspaper/ journalism). In addition to naming authority-related workplaces, BSs also include logos indicating positions of power. One such logo is the scale (representing justice). Similarly, a police cap seen from the rear window identifies the driver as a police officer. Similar logos are the red crescent (for "doctor") and the logo of a tooth and the red crescent for "dentist". Similarly, the golden eagle logo represents the police force, armed forces, and the presidential office, all of which are positions of authority. It is worth noting that a few BSs take the form of a large logo of the golden eagle covering the whole rear window, or a less-imposing small sticker in the corner of the rear window, or a metal badge attached to the license plate.

\subsubsection{Car make}

This category was covered equally by all three car types. Cars are generally considered a symbol of mastery, power and social distinction. Luxury cars are personal markers of authority (e.g. profession) and/or wealth (e.g. brand names). The make of a German car such as "Mercedes" or "BMW" displayed in a large sized logo, filling the rear window, redundantly magnifying what can be seen anyway, seems to emphasize the value of the car make as seen by the driver and imposing it on the observation of all on-lookers as a status marker. Similar BSs further attached to a car rear window displayed such prestigious makes as BMW, Citroën; Matrix; civic; Honda, and Mercedes. Even less expensive and therefore less prestigious cars displayed BSs with their makes like "fiat" (with stars all around copying the Sheraton logo with two branches of olive tree). Even more striking are deliberately misplaced logos of car makes incongruous with the real make of the car. Examples of this include "Ferrari" on a Fiat Taxi, "Original 10" license plates on commonplace cars of all three types, EU and "Roma" license plates showing behind the Cairo license plate, "Haima/ Test Drive" plastered on a Hyundai Accent, and the back spare tire of a Suzuki four-wheel drive displaying "Jeep/ the original 4X4/ since 1941/ www.jeep.com.eg". Most striking are jocular, obviously untruthful statements like "I am a baby Mercedes", "My other car is a Porche" (on a Fiat 127), and "I'm a Jaguar in disguise". Such statements demonstrate the status implications of the car make. The same effect is made by BSs referring to the car in first person as in "I am cute", "I am super" and "Look at me". At best these have two possible readings, one by the car and the other by the driver, which demonstrates the social image transferred from the car (and its BSs) to the driver.

\subsubsection{Social activities}

Of all three car types, only P car BSs show an interest in music and audio equipment evident in BSs' reaching $3.7 \%$. The ten BSs used in this category include three humorous Sony Xplod BSs, as well as other audio equipment brands like "Pioneer", heavy metal music bands like "Metallica", and even favorite singers like "Eminem". This suggests the teenage-related interest in music. 
BSs are also used by activists like charity group members and anti-drug campaigns which try to influence and encourage people to take action. Most of these use the imperative structure to persuade people to carry out the advertised action. "Resala" charity group BSs like "we wanna see your smile/ RESALA / رسالة/www.resala.org/ 07777100" and the bilingual antidrug BS “ أوقف المخدرات / غير حياتك "stop drugs ... change your life" are examples of this.

\subsubsection{Brand names}

Another identity-related category of BS involves the display of brand names. Mainly on $\mathrm{P}$ cars (frequencies are $\mathrm{P}=10 \%, \mathrm{~T}=$ $2.1 \%, S=1.7 \%$ ) and exclusively in English (except for $1 \mathrm{BS}$ in French), the language of prestige and social standing. The abundance of P-car use of brand-name BSs reflects the status consciousness associated with such brands. Brand BSs in the corpus cover four types of designer products. One such type is designer sunglasses "Ray Ban" and designer clothes like "Carbon", "JB collection: parce que je suis différente", "Momo", and shoes like "Timberland" and "Quicksilver". While the brand of drivers' clothes cannot be seen from outside the car while they drive, a BS would give the necessary look of affluent, neat and stylish. Another category of designer product BSs centers around sports gear like "Puma", "Nike" and "Do it", "Quicksilver", and "Wilson", giving the impression of affluence, social class, fitness and youth. A third category of brand-name BSs includes audio equipment like "Woof .. woof .. woof .. / woofers!!! / Xplod/ SONY", "Xplod/ on da road / SONY", "This car may be Xploded!", and "No I won't turn it down! Xplod" as well as "Pioneer", one of the top brands in car audio equipment. The display of such high quality audio equipment as BSs reflects on the driver's affluence and personality as cool and investing in music. Another brand category shown in BSs revolves around drinks like "Dr Pepper" (an expensive elite imported soft drink) and restaurants like "Smiley's Grill" advertises a fast-food place and "PAPASBAR HRG/ www.papasbar.com/ highlife in Hurgada", a commercial advertising a whole style of life and drinking bar. Finally, a number of BSs advertise car spare parts and car maintenance product brands like "Helix" car oil. "Mobil command performance" a whole line of car maintenance, "Tawdeeb.com / the official website of car tuning", "Total" oil and gas company, and insurance companies like "Policy shop / the insurance company". By placing all such brand-name BSs on their cars, drivers use BSs to compensate for the invisibility of other status markers while they sit in their cars. Such BSs reflect status consciousness and provide individuals with means of social mobility and exhibitionism. In this way, drivers use BSs to identify their name, nickname, occupation, recreation activities, status symbols and products to assert and elevate their status.

\subsection{Self praise}

This is equally produced by all three car types $(P=10.7 \%, T=10.7 \%, S=13.4 \%)$. Some BSs include evaluative statements comparing the driver to others to show his superiority to other drivers and/or onlookers. These include "prestige", "pacha", "royal", "exclusive", "I am cute", "ماليش بديل" (I have no alternative/ substitute/equal), "I am super", "I may be slow but I'm ahead of you", "Nobody's perfect; I have [sic.] an exception", "unique by nature", "احنا الأساس وعلمنا كل الناس" (i.e. we're the

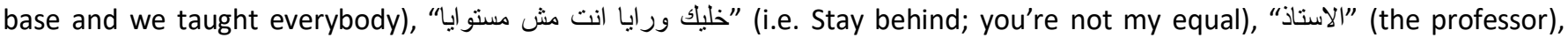
" الكبير كبير" (i.e. The chief is superior), "زيزو واحد بس "ن.e. Zizo, one of a kind). They also include metaphors implying praise like

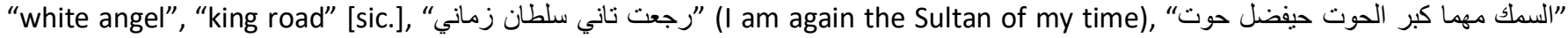
(However large the fish get, a whale is a whale), "النجم" (the star), "فارس المدينة" (the city knight) and "أنابا يالاه" (I'm the boss, boy). They also include comparative and superlative adjectives comparing the driver and/or the car to others like "first quality", "I'm faster" and "Simply the best - No. 1".

\subsection{Hostility and recklessness}

Expressive speech acts involving a show of assertiveness are regarded as trendy, partly due to being rebellious, defying and even rejecting norms of power or good behavior, and partly for being cool and manly and are not to be taken too seriously. Aggression is regarded as "cool" especially among teenagers, an interviewee clarified, asserting friendship in what Leech (1983) calls "Banter", i.e. impoliteness to show solidarity, and to reject the authority of the institution, parents, officers, and adults in general. Frequencies are $\mathrm{P}=11.8 \%, \mathrm{~T}=3.5 \%, \mathrm{~S}=8.7 \%$. Some of these $\mathrm{BSs}$ (especially the ones by $\mathrm{P}$ ) are related to devil worshipping involving offensive statements and profanities, like "Opjection" [sic.], "Veto", "Angryyyy", "Born to fight", "Devil inside", "Pleased to beat you", "Venom", "Ya semmm", "No friends", "I hate people", "Life hates me" and "Don't follow me", while others (especially the ones by S) complain and protest against injustice, or against aggressive fellow drivers who rush and violate traffic rules, overtake and race to get passengers first. They include complaints like "الظالم ليه يوم (i.e. the unjust

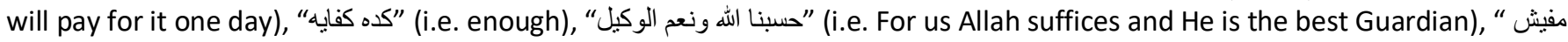

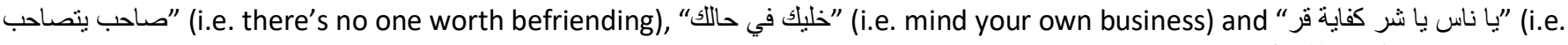
O you evil people, stop envying me), and aggression like "If u touch my car, l'll touch ur girl!", "انت ولا حاجه" (i.e. you are nothing), "بلاش عناد" (i.e. don't be obstinate), "خليك ورايا انت مش مستو ايا" (i.e. stay behind; you're not my equal). While some BSs are anti-social like "Devil inside", "My door is always open so feel free to leave", and "Opjection" [sic.], others show hostility, challenge and even threaten onlookers like "If u touch my car, l'll touch ur girl", and "your time end", "ولا كلمة" (Not one 


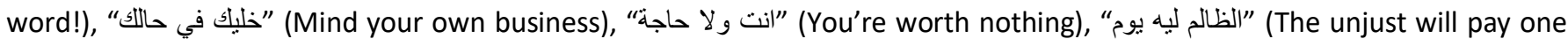
day), "يا ناس يا شر كفاية قر" (O, you evil people, stop envying me). On interviewing them, some drivers said they meant these as a joke while others said they meant to stop others trespassing their lane in the street or overspeeding competitively to get passengers before they get on another taxi or shuttle.

Additionally, reckless behavior is demonstrated by all three car types alike, though at a lower frequency $(P=2.2 \%, T=1.4 \%$, $\mathrm{S}=1.1 \%$ ). Examples of recklessness demonstrate drivers' fun loving attitude, challenging "good behaviour" and are to be taken light-heartedly as humorous. Examples include "Angel by day, devil by night", "Born to be wild", "Born to party, forced to work", and "No fear", all implying a "cool" and reckless attitude.

\subsection{Driving instructions}

Expectedly, many BSs display car information like sales retailer name, or the number of passengers permitted on taxis " 4 "راكب" (four passengers), working hours and fuel type "السيارة تدار بالغاز الطبيعي" (i.e. operated with natural gas). However, less expectedly, a considerable proportion of BSs are expressions of drivers' pride in their own driving skill and expertise. These often include imperative structures instructing other drivers on how to drive or how to treat one's car. They occur in the corpus at the frequency of 7.4\% for P, 2.1\% for T, and 3.5\% for S. Examples include "Drive it like you stole it", "Drive safely / don't learn safety by accident", "Don't follow me / I'm lost too", "Forget about world peace/ visualize using your turn signal", "Shut up and drive”, "خليك ورايا انت مش مستو ايا" (i.e. stay behind, you're not up to my level), and "يا تهدي يا تعدي" (i.e. Slow down or take over).

Moreover, many car BSs address the issue of speed, often bragging about their own speed and/or challenging others to join them in a race. This conceptual domain is more frequent on $\mathrm{P}(7 \%)$ than $\mathrm{T}(1.4 \%)$ and $\mathrm{S}(1.7 \%)$. Some BSs assert the driver's speed like "I'm faster", "Roadmaster", "2 fast 2 furious", "maximum speed, maximum performance" and "Top speed". Others challenge other drivers to chase, confident of their own speed and prospective victory as in "Chase", "Follow me if you can", "Drive it like you stole it" and "Pleased to beat you". Still others name car and motorcycle racing sport events like "Around the track", "Ralli Art", "Formula 1" and "SSCA racing". Finally, some just mention the idea of speed as a prominent value e.g. "Speed", "Racing", "Ghost", and "Auto meter" (with the graphic of a horse and the speedometer). Speed and driving expertise are thus manipulated as sources of pride and self praise.

\subsection{Romance}

Another conceptual domain frequently used by $\mathrm{P}$ cars (8.5\%) in contrast to $2.1 \%$ by $\mathrm{T}$ and $1.1 \%$ by $\mathrm{S}$ is the expression of romance, sexual bragging and soliciting attention or rejecting solicitation. Many BSs explicitly assert the driver's involvement in a love story through such phrases as "Just for you", "ملك روحي" (My soul mate), "Just married", "Married and happy", "Love", and even "I love you" and "Mad about you" either addressing a specific third person the driver has in mind, or an indefinite referent, thus merely expressing a general interest in being in love. A similar set of BSs give voice to the driver's sexual bragging about his romantic adventures like "Angel by day, devil by night", "Life is too short to date ugly girls" and "Naughty". Some express the driver's availability for love, relationships, affairs or marriage; and some even go to the extent of explicitly soliciting interest of the opposite sex through their BSs. Traditional gender roles seem to materialize here where some boys' cars invite girls to date explicitly as in "Girls ride for free", "Kiss me, I'm drunk", "Let's not meet by accident" and "Look at me" while some girls play hard to get, rejecting solicitation and/or express their unavailability for love relations through BSs such as "Don't even think of it", "Number busy" and "Back off, I'm not that type of car". A final set of romancerelated BSs make subtle jokes and innuendos like "Smile, it's the second best thing your lips can do" and "Well-behaved women rarely make history".

\subsection{Ideological proverbials}

One of the conceptual domains that differ in both frequency and content is the area of ideological BSs. These usually constitute philosophical and social advice and popular wisdom, whether already known or coined by the driver. On the one hand, $\mathrm{P}$ cars seem to include many ready-made, mass-mediated, witty English stickers plastered on the cars, reflecting international topics like peace, the environment and meditation. Among these are the all-too-common "Same shit different day", "Visualize peace", Think green", "Today is the first day of the rest of your life", "Why no gain with no pain?" and "Think globally, act locally". These reach the frequency of $5.5 \%$ of P cars while T cars have $11.4 \%$ of their BSs and S buses have $8.1 \%$ revolving around proverbials. The BSs painted on $\mathrm{T}$ and $\mathrm{S}$ also differ from $\mathrm{P}$ in the topics they handle and the medium, being mostly in Arabic. They handle such topics as social injustice as in "الظالم ليه يوم"(The unjust will pay one day), the absence of

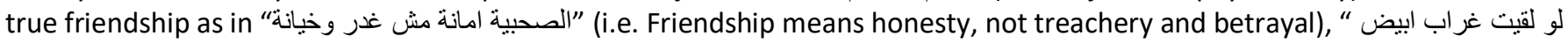
"نلافي صاحب مخلص (i.e. If you find a white crow, then you can find a faithful friend), "عناب الندل اجتنابه" (The best way to blame a

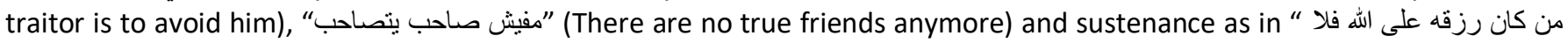
"يحزن "(The one who counts on the Lord for sustenance should not be upset), and "انله يبسط الرزق لمن يثاء ويقبض "(God 
provides sustenance and suspends it as He wishes). There are also a handful of witty metaphorical proverbials handling such

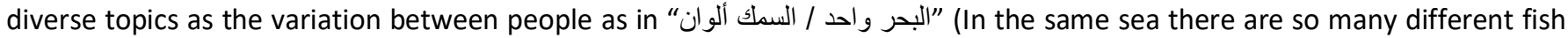
types) and the unshakable seniority of the powerful as in "السمك مهما كبر الحوت هيفضل حوت "However large the fish get, a whale is a whale). Additionally, some BSs handle social criticism. While P cars display ready-made imported BSs in English as "سو اقين آخر زمن" explained above, T and S cars express their dissatisfaction with the lack of moral standards in such BSs as

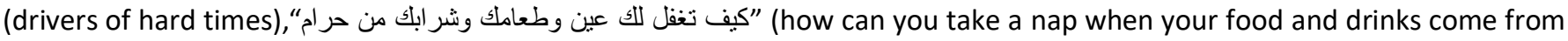

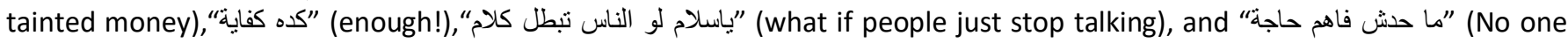
understands anything) commenting on chaotic traffic or even chaotic politics.

A very small subset of ideological BSs tackle political issues (only 2 BSs by each car type i.e. around 1\%). One of these tackles the Palestinian issue, namely "ثيخ قعيد أيقظ أمة منى تتحرك أصحاب الهمة" (i.e. A crippled old man awakened a nation; when will people with resolution take action?) inviting onlookers to avenge Palestinian Sheikh Yassin who was assassinated in 2004; another is a pronouncement of faith "لا اله الا اله محم رسول اله "(There is no god but Allah; Mohammad is His messenger) which becomes politicized when accompanied by a sword filling the whole rear window, thus seeming to belong to fanatic political Islam mixing religion and politics and fighting those who disagree. The film title "المواطن مصري" (The citizen is Egyptian) accompanied by the Egyptian flag seems to assert the driver's patriotism. This relative absence of political BSs on cars was attributed by interviewees to drivers' fear of their cars getting damaged by different political parties or of being harassed by the police if they dare voice any anti-governmental sentiments.

\section{7. "Rizq" (or sustenance)}

All vehicles face risks of road safety; however, as $\mathrm{T}$ and $\mathrm{S}$ are used as a business and a source of income, this poses other risks involved in driving: safety and profit. There is always the fear of road accidents harming car, driver and passengers as well as pedestrians; of officers suspending the car or fining the driver; and of not making enough money as a profit. This gives rise to a whole set of expressed concerns and amulets to increase profit, avoid such risks and avert the evil eye. Only $\mathrm{T}$ and $\mathrm{S}$ show BSs addressing the topic of sustenance at the frequencies of $5.7 \%$ and $5.2 \%$ respectively, all in Arabic due to their culturalspecific nature. These include "من كان رزقه على الله فلا يحزن" (The one who counts on the Lord for sustenance should not be

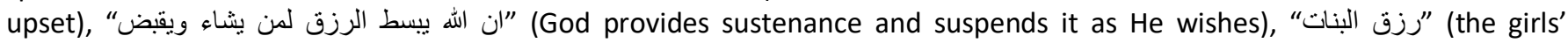
income), "ياناس الرزق لو بالجري ما كانش حد سبقني" (i.e. Folks, if sustenance came through speeding, no one would outstrip me),

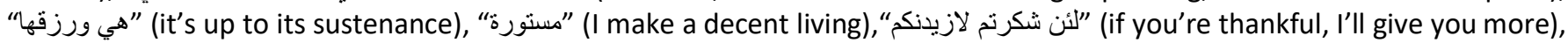
and "ي الناس يا فل الرزق للكي" (O sweet people, sustenance is for all). Most of these BSs imply complaints as to the scarcity of income as in "سالنا ربنا عطانا / وعيون الناس مش ساييانال "We asked the :Lord and he gave us but people's eyes won't leave us[alone]), which could be genuine or motivated by envy as explained below.

\subsection{Envy}

According to Mughazy (1999), Egyptians believe that the evil eye is invoked when others express admiration toward valuable possessions, resulting in having a fatal car crash, low income or unemployment, or police harassment. They follow certain strategies to ward off the potential effects of the evil eye, with BSs assuring that there is nothing special or unique about the car and implying there is no motive for being envious. BSs also use religious and secular formulas as well as nonverbal amulets to bring prosperity and good income as well as invoke God's protection from envy, harm, accidents, unemployment and police harassment. In addition, nonverbal icons are used to avert the evil eye, e.g. the drawing of an open palm, sheepblood prints, a string of blue beads or a hanging old shoe.

One of the most pervasive domains in both Ts and Ss, envy-related BSs had frequencies of $6.2 \%$ for Ps, but $22 \%$ for Ts, and $26.9 \%$ for Ss. All three kinds of vehicles had BSs exclusively in Arabic to avert / ward off the evil eye and seek God's protection. One type of protection from the evil eye involves BSs citing Quranic verses and prayers praising the Prophet and accepting God's boon and bounty. Examples are "يارب سترك" (i.e. O Lord, [grant me] your protection), "فاله خير حافظا وهو أرحم الهين

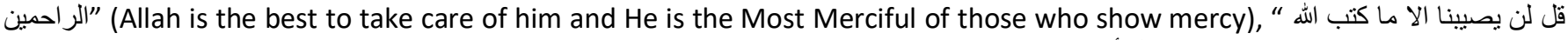

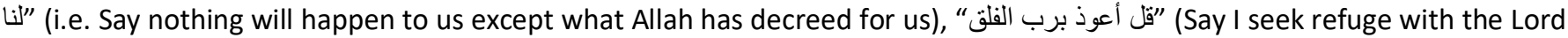

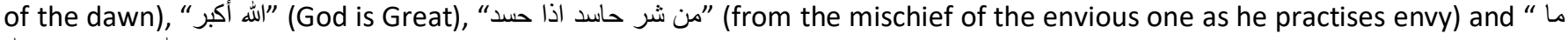
"شاء اله لا قوة الا باله " (This is Allah's will; there is no power but from Allah). In addition to such religious expressions, some secular formulas are used in BSs to award the evil eye, exclusively on T and S cars. These include "يأ ناس يا شر كفاية قراس you evil people, stop envying me), "عضدة أسد ولا نظرة حسد" (I would take the bite of a lion but not the look of the evil eye), and

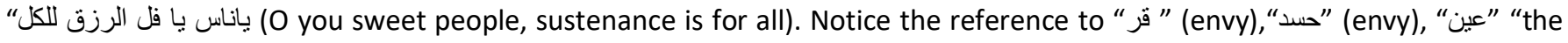
eye", "عين" "the look" of evil that scares drivers and motivates such BSs. In addition, complaints and formulaic phrases are used (both religious and secular), expressing the driver's dissatisfaction and denying having anything special or unique that would attract the wrong kind of attention. Drivers gripe about the lack of resources and ask others to mind their own 
business and stop envying them. Among such envy-related complaints are the BSs "الحلوة دي خوخة وجت من بعد دوخة is a beauty and I got it after a lot of hard work), "الغالبان" (The needy/ miserable), "ياناس سيبوني أسدد ديوني" (O folks, let me pay back my debts), “ياناس يا شر كفاية قر" (i.e. O you evil people, stop envying me), and "اللي جاي رايح وبلاش فضايح" (What money I make I have to spend; what a shame). Complaints are also implicit in some "for sale" notes attached to car rear windows. Apart from genuine "for sale" notices like "للإليع بجد" (For sale; serious!), a subset imply dissatisfaction with the car as

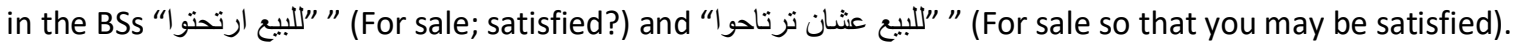

\subsection{Religious expressions}

Another pervasive domain of BSs is that of religious expressions and faith pronouncement. This includes supplication, citations from the Quran, Bible and the Tradition, and explicit religious advice. The pervasiveness of such religious BSs especially with Ts $(42 \%)$ and Ss (26\%) as opposed to Ps (10\%) can be attributed to their serious motivation for being on the road - to earn their living. As people in general tend to resort to religion for self-assurance against possible anxiety or actual hardships, among a host of other reasons, religious expressions are found in BSs on all three car types alike, and seem to fall into five categories: supplication, prayers on the Prophet, verses from the Quran and the Bible, ritual remembrance of God, and religious advice. First, "Doaa" or supplication is used not only to seek God's love for heavenly reward, but also to ask Him to protect the driver, his loved ones and the car from the dangers of the road (i.e. accidents, traffic police harassment, etc.), to ward off the evil eye and to grant the driver more money, safety and happiness. Examples of supplication BSs include "ديارب

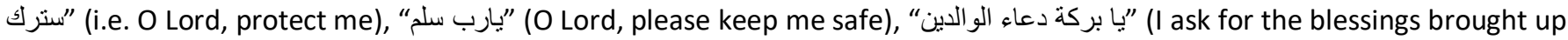

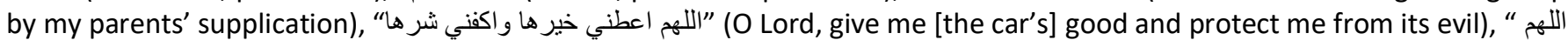
(I seek refuge with the Lord's perfect words from the devil and the evil eye) and "سيري على بركة اللهة (Go with God's blessings). Christian equivalents included "اللهم التفت الى معونتي" (Gode please pay attention to assisting me).

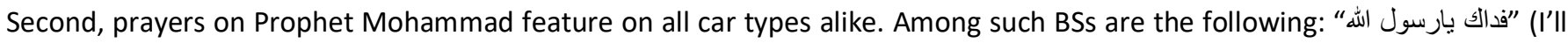

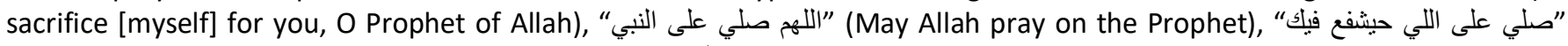

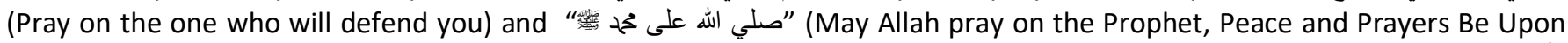
Him). The Christian equivalent of this is the naming of Christian saints invoking their blessings and protection like " أم النور (literally, Mother of Light, i.e. Virgin Mary), "مار جرجس" (Saint George) and "البطل الروماني" (the Roman Hero, i.e. Saint George). Third, verses are cited directly from the Quran and the Bible for their blessings and heavenly reward as well as for their

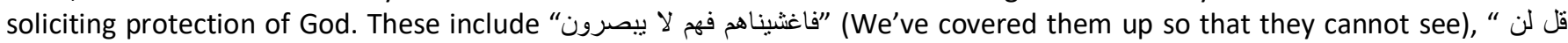

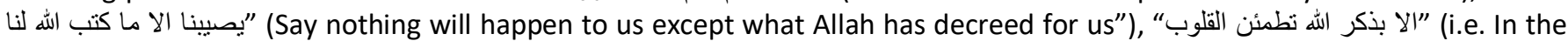
rememberance of Allah, hearts find satisfaction) and the Biblical "الرب راعي" (The Lord is my Shepherd) as well as the examples cited in the sections above.

Fourth, "Dhikr" or ritual remembrance is included in a large number of BSs. Interviewees explained that this is a means of achieving moral and social reform especially with the increasing rate of visible corruption and social misconduct. One interviewee said that by painting "dhikr" on his car, he seeks to remind himself and others to worship God in word and deed.

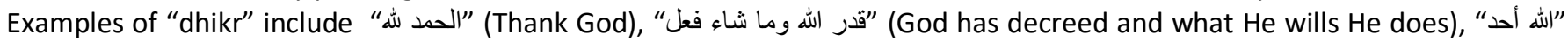

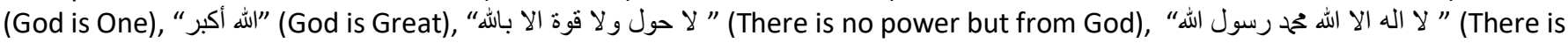
no god but God; Mohammad is His messenger) and "هذا من فضل ربي" (This is from the Grace of God). Finally, explicit religious advice is given in a number of BSs with the intention, according to a car driver, of encouraging on-lookers to read the religious advice, rethink their actions and eventually adopt more religious behaviour. Another driver explained his use $f$ such didactic BSs in terms of his attempt to remind himself and others to do the right thing. Included in this category are such BSs as " اذكر "ارحموا من في الارض يرحمك من في السماء" "(Mention/ remember God), "(Hercy on those on earth so that the One in

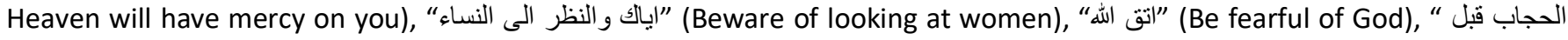
"الحساب" ([Take] the veil before doomsday). The use of imperative structure invites readers to respond appropriately. All in all, religious BSs function as equivalent to good luck charms and amulets, inspirational thoughts and symbols of faith. Their preponderance may have implications on Egyptian drivers' preoccupation with religious sayings.

\subsection{Humour}

BSs can be a delightful form of self-expression to entertain other drivers on the road, or friends and neighbors when the car is parked near one's home. Examples of humor in the corpus of the present study come almost exclusively from P cars. As Case observes (1992), older and less impressive cars display humorous comments making fun of the condition of the car or the driver/owner. Egyptian BSs of this category include "I'm a baby Mercedes" and "My other car is a Porsche", both making fun of the car they are plastered to. Similarly, some BSs joke with the onlookers in the car behind by making fun of their driving as in "Forget about world peace/ visualize using your turn signal", "Don't drink and drive / smoke and fly", "Pleased to beat you", "خليك ورايا انت مش مستو ايا" (i.e. Stay behind; you're not my equal), and "I may be slow / but I'm ahead of you". Some BSs 
based on intertextuality are jocular in nature like "Most wanted", "killer" or "ghost", all of which belong to the script of horror and action films and are not to be taken seriously. Humour is also encountered in ready-made, imported BSs such as "Smile/ it's the second best thing your lips can do" and "Well-behaved women / rarely make history". In the Sony BS "Woof .. woof .. woof .. / woofers!!! / Xplod/ on da road / SONY", the humour arising from realizing the pun of the onomatopoeia of the dog's barking and the "subwoofer" equipment produced by Sony was not understood by many interviewees. In contrast to such ready-made humorous BSs, some jokes are based on Egyptian socio-cultural knowledge, thus building rapport and involvement with onlookers. Examples of this are "Afrotto (a comic play character's name derived from the word "genie" in Arabic) and "ya semmm" (i.e. you beast! or how horrid!, usually said by a woman rejecting men who try to make out or flirt with her). Finally, a group of symbolic BSs remind onlookers of the fun aspects of certain animation film characters such as "Garfield", "Tweeti" and "fido dido". Such humor being almost absent from T and S cars can be telling about the degree of their involvement in the struggle for a living in the middle of the traffic jungle.

\subsection{Multiple possible interpretations}

In interpreting and categorizing BSs, interviews and questionnaires were designed to obtain some degree of reliability of interpretation. The results were mostly unanimous with the exception of two categories: multiple interpretations and no interpretation. On the one hand, some BSs received divergent and at times conflicting interpretations by different interviewees. For instance, "مات الكلام"(Words are dead) on T and S alike, received different readings. According to some interviewees, it indicates either the driver's snobbery in not speaking to those he doesn't like; to others it denotes the use of force against passengers who don't pay the fare. Similarly, the BS, "البطل الروماني" (The Roman Hero) was given different interpretations by different interviewees. Some interpreted it correctly as in the Christian creed where it refers to Saint Mari Girgis, or Saint George, to use his Latinate name, invoking his blessings, while others understood it to refer to Roman gladiators representing strength and power.

On the other hand, some BSs defied interpretation and were opaque to interviewees though appearing on numerous cars, probably just because they seemed cute or "cool". For instance, the picture of Guevara, the Latin American anti-colonial hero, was often placed on S car rears next to BSs of flowers and a pair of beautiful eyes. When one driver was shown that BS and was asked who was in the picture, he responded that he thought it belonged to a pop singer, judging from his headpiece. Similarly, the Japanese and Chinese BSs on some cars were unintelligible to all the interviewees, thus probably indicating their users' lack of interest in communicating with the general public and restricting communication to fellow Japanese or Chinese speakers. In a similar way, acronyms and brand names and other symbols of limited frequency of use (such as P-Plus, Wilson, Apex-4, or 07-7) probably indicate drivers' not wanting to communicate except with the limited community of their own circle and like-minded onlookers.

\section{Conclusion}

A number of conclusions can be reached from the above analysis of Egyptian BSs in three different car types. In terms of engagement, the dialogic interactional nature of BSs is enhanced through the use of certain tools of engaging with onlookers or disengaging from them. As Fiske comments, "a car is not just transport, but a speech act" (1989). Another finding relates to the exhibitionism evident in the BSs employed by $\mathrm{P}$ cars through the status markers which seem to run through the majority of their BSs (including alma mater, profession, brand names and car make). Even the imported BSs of Western culture reflect a tendency to adopt different cultural values like the ideological and the playful hostility and recklessness BSs. This estrangement from the local culture is further enhanced with the highly frequent use of English in the majority of P-car BSs (84\%) helping them communicate with like-minded onlookers and look down upon vehicles that do not match their status. The P-car overuse of English suggests an attempt to seek esteem and values from other cultures. Another finding has to do with the abundance of religious and envy-averting BSs employed by all car types, though more frequently so by Ts and Ss. This could be explained in terms of the dangers specially threatening Ts and Ss on the road, including accidents, fines, competition over passengers, rows with passengers, police harassment and traffic jams. In the face of all these threats, drivers blame them on the evil eye and resort to religious formulas for protection. One last significant finding is the relative absence of political BSs counterbalanced with a large number of humorous and intertextual BSs alluding to films, soap operas and the like. This underlines a lack of political agency and a seeming political vacuum (at least on record) and fills it with television drama as a substitute for the drama of the real world.

Further research can handle such areas as what types of drivers and/or cars show which types of signs (which can be classified by geographical location, profession, education, or socio-economic background). It could also investigate the combinations of BSs on a single car and the dialogue between congruous and/or incongruous BSs such as "Just do it" and "Don't do it"; "Friends" and "No friends"; or "Follow me" and "Don't follow me". Research could also examine other 
discourse types negotiating aspects of all arrangements under which we live such as different types of road signs referring to speed limits, prohibiting certain actions and constraining individual driver and pedestrian behaviours.

\section{Acknowledgements:}

I wish to acknowledge the contributions of the graduate Discourse Analysis class of 2008-2009 at Cairo University as well as my friends and colleagues Amani Badawy, Amany Toma, Hala Yusry and Manar Shalaby for their help in the interpretation of many bumper stickers and/or responding to the questionnaire and/or interview questions. I would also like to thank the anonymous interviewees for their valuable comments. Any shortcomings are mine.

\section{References}

[1] Banning, J. (1996). Bumper sticker ethnography: A study of campus culture. The Campus Ecologist, 14 (3), 1- 4. http://www.campusecologist.org/cen/v14n3.htm (accessed August 12, 2008).

https://citeseerx.ist.psu.edu/viewdoc/download?doi=10.1.1.575.7856\&rep=rep1\&type=pdf (accessed September 11, 2020)

[2] Bloch, L.-R. (2000). Mobile discourse: Political bumper stickers as a communication event in Israel. Journal of Communication, 50 (2): 48-76.

[3] Case, C. E. (1992). Bumper stickers and car signs ideology and identity. Journal of Popular Culture, 26 (3): 107-120.

[4] Chiluwa, I. (2008). Religious vehicle stickers in Nigeria: A discourse of identity, faith and social vision. Discourse and Communication, 2 (4): 371-387.

[5] Endersby, J.W. and Towle, M.J. (1996). Tailgate partisanship: Political and social expression through bumper stickers. Social Science Journal, 33 (3): 307-319.

[6] Fairclough, Norman. (1989). Language and Power. London: Longman.

[7] Fiske, J. (1989). Understanding Popular Culture. London: Routledge.

[8] Goffman, E. (1979). Footing. Semiotica, 25: 1-29.

[9] Halliday, M.A.K. (1985). An Introduction to Functional Grammar. London: Edward Arnold.

[10] Hyland, K. (2005). Metadiscourse: Exploring interaction in writing. London: Continuum.

[11] Krippendorff, K. (1980). Content Analysis: An introduction to its methodology. Beverly Hills, CA: Sage Publications.

[12] Kristeva, Julia. (1991). Strangers to Ourselves. New York, NY: Harvester Wheatsheaf.

[13] Kurzon, D. (1997). Deixis and background knowledge in the humor of car-bumper stickers. Semiotica, 113 (3/4): 347-368.

[14] Lammie, K. and Humphreys, L. (2004). "No votes for turncoats": An analysis of bumper stickers at public discourse. Unpublished paper presented at the 2004 annual meeting of the National Communication Association, November 11-14, Chicago, Illinois. <http://convention.allacademic. com/nca2004/session_info.html?c_session_id=2026\&dtr_id=1252> (accessed February 12, 2008).

[15] Leech, G.N. (1983). Principles of Pragmatics. London: Longman.

[16] Mughazy, M. (1999). Pragmatics of the evil eye in Egyptian Arabic. ERIC document, ED 432921.

[17] Newhagen, J. and Ancell, M. (1995). The expression of emotion and social status in the language of bumper stickers. Journal of Language and Social Psychology, 14 (3): 312-323.

[18] Nilsen, D. (1980). The grammar of graffiti. American Speech, 55 (3): 234-239.

[19] Noble, G. and Baldwin, R. (2001). Sly chicks and troublemakers: Car stickers, nonsense and the allure of strangeness. Social Semiotics, 11 (1): 75-89.

[20] Salamon, H. (2001). Political bumper stickers in contemporary Israel: Folklore as an emotional battleground, Journal of American Folklore, 114 (453): 277-308.

[21] Searle, John R. (1976). The classification of illocutionary acts. Language in Society, 5: 1-24.

[22] Shore, Scott. (2003). Bumper sticker stupidity. http://www.intellectualconservative.com/2003/06/02/bumper-sticker-stupidity/ (accessed March 8, 2009). 